\title{
Trabalho em saúde, corpo e subjetivação capitalística
}

\author{
Work on health, body and capitalist subjectivation \\ Trabajo en salud, cuerpo y subjetivación capitalística
}

Alcindo Antônio Ferla(a)

A primeira manifestação sobre o artigo de Célia Iriart e Emerson Merhy é comemorar a contribuição ao campo da Saúde Coletiva nos últimos vinte anos da vertente que nos habituamos a denominar de "micropolítica do trabalho em saúde" ${ }^{1}$, envolvendo estudos que tornam visíveis arranjos tecnológicos e forças em sistemas e serviços de saúde que não são captáveis por leituras disciplinares e pelas perspectivas mais clássicas. Os estudos de Iriart sobre reformas do setor de saúde e as estratégias de regulação da assistência, controle de custos e qualidade dos sistemas de cuidado ${ }^{2}$ em diversos países contribuíram com a constituição do campo da Saúde Coletiva ${ }^{1,2}$. Merhy é líder e artífice da produção sobre micropolítica do trabalho e, desde a década de 1980, produz análises que permitem identificar, ao mesmo tempo, questões estruturais e a dimensão relacional do trabalho no cotidiano, em análises mais complexas do que modelos assistenciais caracterizados centralmente pelo efeito de políticas e interesses corporativos ${ }^{1,3}$. Parte das produções de ambos foi feita em parceria, gerando conceitos que estão sendo reinterpretados no artigo. As "modelagens tecnoassistenciais" que se tornam visíveis a partir da vertente "micropolítica" são a materialização da vitalidade do campo da Saúde Coletiva, quando compreendido a partir de tensionamentos interdisciplinares e na relação com o cotidiano dos sistemas, como descreve Madel Luz ${ }^{4}$.

A análise das estratégias de regulação/indução do consumo por parte do complexo médico-industrial, incidindo sobre o usuário para modular demandas aos sistemas de saúde, é contribuição importante da produção teórica dos autores. Apenas com a tradição de análises centradas no estudo da organização e do funcionamento geral dos sistemas de saúde percebem-se insuficiências para compreender a complexa trama de forças que atuam nesse cenário e para propor mecanismos de regulação pública capazes de incidir na produção social da demanda. A dificuldade de superar a visão dicotômica de lógicas diversas entre o público e o privado produz discursos centrados na denúncia e proposições frágeis para regular relações de consumo e de produção, inclusive dos imaginários dos diferentes atores. Essa crise de pensamento gera desencontros visíveis entre expectativas de cuidado e o cuidado efetivamente prestado, com um "triunfo" 
da lógica capitalística, seja pelo predomínio de modelos embasados em tecnologias duras e leve/duras, seja pela vigência da lógica do problema-solução, empobrecendo a clínica no cotidiano.

A ideia da "clínica de um corpo sem órgãos" é relevante para pensar o cuidado e, sem dúvida, também para analisar a produção de imaginários e mecanismos de microrregulação do consumo de bens e serviços. É interessante a construção analítica apresentada no artigo, que toma a produção de subjetividades para o consumo a partir da transformação do usuário em consumidor, como na biomedicalização da vida. Em trabalho com as ofertas assistenciais de planos e seguros privados de saúde, identificamos um mix de arranjos em que as estratégias de regulação utilizadas pelas empresas recaiam sobre os usuários, seja limitando o acesso à maior densidade tecnológica pela captura da autonomia profissional ou até fornecendo um "esclarecimento" sobre direitos em relação ao Sistema Único de Saúde ${ }^{5}$, induzindo ações de judicialização. No artigo em debate, os autores desvelam uma estratégia importante de articulação entre a clínica "das doenças" e a biomedicalização da prevenção e promoção à saúde, com estratégias de subjetivação que instituem um mandato moral de "vida saudável" aos usuários, ao tempo em que os constituem como vigilantes também das ofertas assistenciais que "devem" consumir.

Em pesquisa sobre retórica utilizada na divulgação científica em capas de revistas impressas e comercializadas em bancas de jornais ${ }^{6}$, coordenada por Madel Luz, chamou-nos atenção a visibilidade sobre as práticas integrativas e complementares e sobre hábitos saudáveis de vida. Tal processo é similar ao observado pelos autores nas estratégias do capital financeiro e, da mesma forma, parece inicialmente um movimento centrado no "esclarecimento" sobre os diferentes riscos à saúde a que estão submetidas pessoas e coletividades. Como na análise dos autores, identificamos uma transposição da imagem do corpo configurado anatomicamente como um conjunto equilibrado de órgãos e submetido às diferentes especialidades para uma produção mais próxima da vigilância e do controle de pessoas e grupos, com a produção de uma "cultura utópica de saúde" que se expressava em "práticas saudáveis, incluindo um higienismo preventivo presente nos discursos das Biociências, combinado a um projeto de promoção da saúde apoiado em práticas biocientificamente embasadas" 6 (p. 345). Entretanto, diferentemente das estratégias do capital financeiro analisadas pelos autores, na produção científica divulgada pelas revistas parece haver, logo em seguida, a reprodução do corpo/ organismo, revelando uma "superfície interna"7 que, embora atravessada por relações sociais e pelos modos do andar a vida, precisa materializar-se em imagens físicas para a indução de um processo de subjetivação do leitor pelo "esclarecimento". É o caso de cérebros "turbinados" com raios e força elétrica, imagens de órgãos e tecidos tratados graficamente de tal forma a retirar o sangue e os fluidos e animados por movimentos virtuais quadridimensionais, entre outros, buscando o convencimento sobre valores da saúde e da doença.

Reforço aqui "dobra" sutil da análise sobre a retórica das capas de revistas: há uma tensão entre um "corpo" despido "de seus aspectos corpóreos, tais como: sangue, tecidos, sistemas, fluidos e volume" ${ }^{\prime 6}$ (p. 345), similar às estratégias analisadas pelos autores, e um corpo/organismo reconstruído com uma aparência estética mais sedutora e uma dinâmica vital mais "didática", próxima àquela gerada pelas tecnologias de apoio diagnóstico de ponta, com a produção de "órgãos transcorporais". Como dissemos naquela ocasião, o discurso imagético que é fartamente utilizado na divulgação científica parece induzir um imaginário que supera simbolicamente a natureza biológica do corpo humano tal qual é representado desde o fim do século XVI, na nascente da ciência moderna e da biomedicina. O "corpo de órgãos transcorporais" da retórica das revistas de divulgação científica não está dotado de "devir" ou singularidades, mas de uma nova objetividade revelada pelas imagens tratadas tecnologicamente, objetividade necessária para embasar a constituição de consumidores de recursos tecnológicos e terapêuticos sempre renovados, mas "bem prescritos", ou seja, em acordo com as "melhores evidências científicas".

Longe de acreditar que a ciência vigente se descola completamente dos interesses do complexo médico-industrial e do processo capitalístico de subjetivação, parece adequado perceber um pequeno espaço de defasagem entre as duas estratégias, facilmente associáveis a interesses e relações de poder ou, como acenam os autores, de "disputas intercapitalistas". O "regime de produção de verdades" que está diretamente associado aos interesses do complexo médico-industrial e, em 
particular, à indústria de medicamentos, parece voltado ao forjamento de subjetividades para o consumo de equipamentos e insumos, apostando em regular o trabalho dos profissionais. Por outro lado, para o capital financeiro que ingressa fortemente na área da Saúde a partir dos anos 1980, a racionalização de custos é relevante, apostando em um certo grau de autonomia e responsabilização dos consumidores. A produção científica embasa um padrão de subjetividade que, embora inclua o imaginário de um corpo distinto da sua representação biológica clássica, constitui uma compreensão dependente do "domínio científico" e, portanto, tem maior necessidade de reconstituí-lo novamente pela sua dimensão objetiva, devolvendo aos profissionais uma "autonomia" subordinada à ciência", como saber estruturado.

Essa reflexão se articula com o artigo em debate também pela aposta no trabalho vivo em ato no cotidiano e por uma produção pedagógica intensa ${ }^{3}$ no trabalho de cuidado, de gestão, de formação e de participação que permitam avançar na qualidade da atenção oferecida às pessoas e coletividades e na afirmação da saúde como direito das pessoas. Esse movimento somente se realiza com alianças e laços vigorosos entre trabalhadores e usuários, com o fortalecimento de relações democráticas no trabalho e na sociedade e com uma formação ética dos profissionais, tornando-os capazes de usar sua autonomia para ativar a potência e o devir do corpo de cada pessoa e avançar na produção de integralidade.

\section{Referências}

1. Merhy EE. Saúde: cartografia do trabalho vivo. São Paulo: Hucitec; 2002.

2. Iriart C. El sistema de salud de los Estados Unidos: mitos y realidades (Parte I). Saúde em Redes [Internet]. 2016; 2(1):7-21 [citado 28 Maio 2017]. Disponível em: http://revista. redeunida.org.br/ojs/index.php/rede-unida/article/view/665/pdf_26.

3. Ceccim RB, Merhy EE. Um agir micropolítico e pedagógico intenso: a humanização entre laços e perspectivas. Interface (Botucatu). 2009; 13 Supl 1:531-42.

4. Luz MT. Complexidade do campo da Saúde Coletiva: multidisciplinaridade, interdisciplinaridade e transdisciplinaridade de saberes e práticas - análise sócio-histórica de uma trajetória paradigmática. Saúde Soc [Internet]. 2009; 18(2):304-11 [citado 28 Maio 2017]. Disponível em: http://www.scielo.br/pdf/sausoc/v18n2/13.pdf.

5. Ferla AA, Trepte RF, Possa LB, Schweicardt JC, Lima RTS, Plentz LM. A interface entre os sistemas privado e público de saúde na política de saúde mental: a construção de linhas de cuidado. In: Lozer AC, Godoy CVC, Coelho KSC, Leles FAG, organizadores. Conhecimento técnico-científico para qualificação da Saúde Suplementar. Brasília: OPAS; 2016. p. 85-98.

6. Luz MT, Ferla AA, Machado AS, Dall Alba R. Retórica na divulgação científica do imaginário de vida e saúde: uma proposta metodológica de análise. Interface (Botucatu). 2017; 21(61):333-47 [citado 28 Maio 2017]. Disponível em: http://www.scielo.br/pdf/ icse/v21n61/1807-5762-icse-1807-576220150797.pdf.

7. Ferla AA. Clínica em movimento: cartografias do cuidado. Caxias do Sul: EDUCS; 2007. 